\title{
Predators of the destructive sea urchin Strongylocentrotus droebachiensis on the Norwegian coast
}

\author{
Camilla With Fagerli ${ }^{1,3, *}$, Kjell Magnus Norderhaug ${ }^{1,3}$, Hartvig Christie ${ }^{1}$, \\ Morten Foldager Pedersen ${ }^{2}$, Stein Fredriksen ${ }^{3}$
}

\author{
${ }^{1}$ Norwegian Institute for Water Research (NIVA), Gaustadalléen 21, 0341 Oslo, Norway \\ ${ }^{2}$ Department of Environmental, Social \& Spatial Change (ENSPAC), Roskilde University, PO Box 260, 4000 Roskilde, Denmark \\ ${ }^{3}$ Department of Biosciences, University of Oslo, PO Box 1066, Blindern, 0316 Oslo, Norway
}

\begin{abstract}
In central Norway, populations of the green sea urchin Strongylocentrotus droebachiensis are collapsing, but the factors controlling its population density have not yet been elucidated. Through field sampling, we identified several sea urchin predators and investigated their predation rates on recently settled $S$. droebachiensis in laboratory experiments. Tethering experiments in kelp forest and on barren ground study sites in the area where sea urchin populations are collapsing confirmed predation by some of the predators tested in laboratory experiments. The edible crab Cancer pagurus was the most efficient sea urchin predator, and it was more abundant at kelp forest sites than on barren grounds. Stocks of C. pagurus have increased dramatically in central Norway since the 1990s, and predation by C. pagurus may contribute to the decline in sea urchin densities, allowing kelp recovery and conferring resilience of the new kelp forest state.
\end{abstract}

KEY WORDS: Predator $\cdot$ Cancer pagurus $\cdot$ Kelp recovery $\cdot$ Laminaria hyperborea $\cdot$ Barren ground

\section{INTRODUCTION}

On the coast of central Norway, kelp Laminaria hyperborea (Gunnerus) Foslie forests are recovering from extensive overgrazing and more than 4 decades of sea urchin dominance (Norderhaug \& Christie 2009). The precipitous decline in the population of green sea urchins Strongylocentrotus droebachiensis O. F. Müller, 1776 seems related to a failure in recruitment, which has coincided with increasing ocean temperatures (Fagerli et al. 2013). Throughout this period of increasing water temperatures and kelp recovery, an abrupt increase in the abundance of the edible crab Cancer pagurus Linnaeus, 1758 has taken place (Woll et al. 2006). As a likely sea urchin predator, the increase in C. pagurus may contribute to the on-going process of kelp recovery.

\footnotetext{
*Corresponding author: camilla.with.fagerli@niva.no
}

Large-scale overgrazing of kelp forests along the west coast of Norway began in the 1970s as a result of a sudden outbreak of the sea urchin population (Norderhaug \& Christie 2009). During the 1980s, the overgrazed area of barren ground had its largest extent, covering approximately $2000 \mathrm{~km}^{2}$ of the Norwegian coastline, from Trønderlag northward $\left(63^{\circ}\right.$ to $71^{\circ} \mathrm{N}$; Sivertsen 1997a,b, Norderhaug \& Christie 2009). While scattered remains of kelp forest prevailed in outer, wave-exposed sites facing the ocean, sea urchins dominated sheltered and moderately wave-exposed areas (Skadsheim et al. 1995, Sivertsen $1997 b)$. Since the 1990 s, nearly $500 \mathrm{~km}^{2}$ of kelp forest have recovered in the previously over-grazed area (Fig. 1). The recovery has progressed from the southernmost part of the overgrazed area and from wave-exposed toward sheltered areas (Norderhaug

( ) NIVA, Univs. of Oslo \& Roskilde 2014. Open Access under Creative Commons by Attribution Licence. Use, distribution and reproduction are unrestricted. Authors and original publication must be credited.

Publisher: Inter-Research · www.int-res.com 


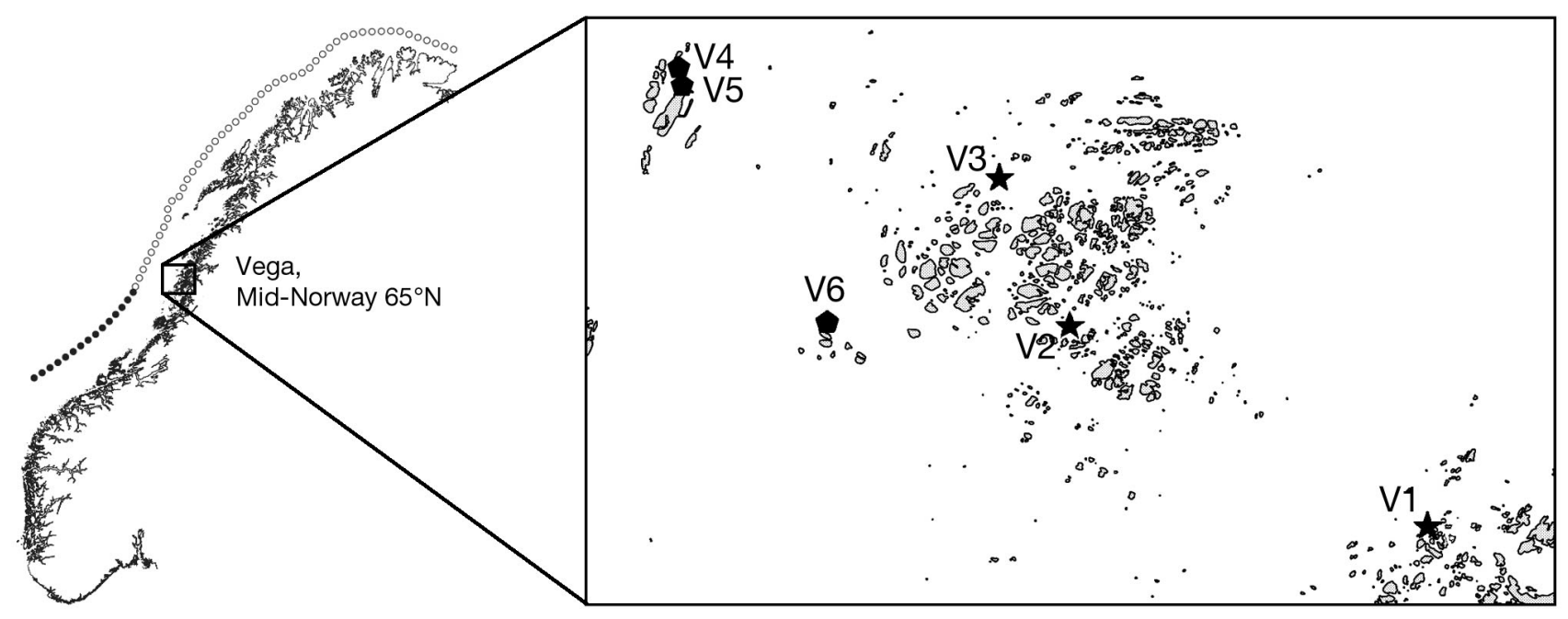

Fig. 1. Norway, showing the study area in Vega and barren ground $(\star)$ and kelp forest $(\bullet)$ stations. The dotted line bordering the coastline marks the coastal area that has suffered from sea urchin overgrazing, with closed circles indicating the area where kelp forest has recovered, and open circles indicating the current area of barren ground (from Norderhaug \& Christie 2009)

\& Christie 2009). By 2007, the southern boundary of barren ground was situated south of Vega, central Norway $\left(65^{\circ} \mathrm{N}\right)$ and, except for some local regrowth, areas farther north still suffer from overgrazing and dominance by sea urchins (Norderhaug \& Christie 2009, Fagerli et al. 2013).

Overgrazing of kelp forests by sea urchins has occurred frequently and triggers phase shifts from diverse and highly productive ecosystems to structurally simple barren grounds (sensu Steneck et al. 2002). Such overgrazing events have been observed worldwide (Dayton 1975, Lawrence 1975, Harrold \& Pearce 1987, Sivertsen 1997b), both as cyclic and short-term events (Scheibling et al. 1999) and as long-lasting events where barren ground replaces kelp forests in a persistent stable state (Sivertsen 2006, Norderhaug \& Christie 2009). The phase shift towards barren ground is triggered by an increasing density of sea urchins (Steneck et al. 2002), whereas the resilience of barren ground is mediated by high densities of sea urchins (Hereu et al. 2004). In order for kelp to recover, an extensive reduction in the sea urchin population is required (Scheibling 1986, Leinaas \& Christie 1996).

Sea urchin population dynamics depend upon factors controlling the supply and arrival of pelagic larvae, on the properties of the benthic habitat where they recruit and on the factors that affect postsettlement mortality such as predation, migration and disease (Roughgarden et al. 1988, Rodríguez et al. 1993, Balch \& Scheibling 2001, Prado et al. 2012). Even though sea urchins overgraze their primary food source, they may sustain high densities for decades in an algal-free habitat due to a high tolerance to low food supply (Levitan 1988, Russell 1998). However, top-down control by predators such as sea otters (Estes et al. 1998), large fish (Steneck et al. 2004), crabs (Clemente et al. 2013, Steneck et al. 2013) and lobster (Ling et al. 2009) has frequently been documented as an important regulating factor which may keep the density of sea urchins low and contribute to maintain intact kelp ecosystems.

The available research on predation on sea urchins from Norway is rather limited, and although Sivertsen (2006) proposed that large fish, sea birds and crabs were potential predators of sea urchins, he did not consider their predation pressure sufficient to limit the sea urchin populations. However, this reasoning was based on mathematical calculations, and neither predation preferences nor predation rates were measured. Furthermore, Sivertsen (2006) concentrated on the interactions between adult sea urchins and their potential predators and did not assess potential predation pressure on juvenile sea urchins. Juvenile sea urchins $(0-20 \mathrm{~mm}$ test diameter) live cryptically, e.g. underneath boulders and in gravel, maerl and kelp holdfasts, probably to escape predation during a phase when their small size makes them vulnerable (Witman 1985, Himmelman 1986, Raymond \& Scheibling 1987). A behavioural shift occurs when the sea urchins become larger. As they increase in size, they emerge from their refuges and become part of the adult population which lives in more open habitats (Himmelman 1986). The small juvenile life stages are potentially susceptible to predation from a much broader range 
of predators than the older and larger life stages (Scheibling \& Robinson 2008, Bonaviri et al. 2012). Predation on young life stages may therefore potentially be high enough to affect demographics and, thus, the population size of sea urchins. An increasing body of work has focussed on the role of small predators that target newly settled sea urchins as a controlling factor for the recruitment and abundance of sea urchins (Rowley 1989, McNaught 1999, Scheibling \& Robinson 2008, Bonaviri et al. 2012, Clemente et al. 2013, Steneck et al. 2013). Rowley (1989) and McNaught (1999) showed that low densities of sea urchins within kelp forests were caused by high post-settlement predation from high numbers of small predators, and Steneck et al. (2002) reported that crab micro-predators may consume entire cohorts of newly settled sea urchins. While barren grounds are characterized by naked substrates and a relatively low biodiversity (Sala \& Zabala 1996, Ling 2008), more than 200 invertebrate species may be found per $\mathrm{m}^{2}$ within a kelp forest (Christie et al. 2003). Predation on newly settled sea urchins may thus represent an important life-history bottleneck for sea urchin populations in areas where kelp forests are recovering and the faunal communities are being re-established.

Stephens (1972) observed failure in the development of Strongylocentrotus droebachiensis larvae at temperatures above $10^{\circ} \mathrm{C}$ and suggested that larval supply is restricted to areas where temperatures during the planktonic phase do not exceed this critical upper limit. Fagerli et al. (2013) studied early recruitment of sea urchins within areas of barren ground in central Norway and found that low recruitment coincided with recent, warmer sea temperatures. Norderhaug \& Christie (2009) observed smaller patches within the kelp recovery area where sea urchins still remain, which indicates that more than one factor may drive the on-going kelp recovery process. While increasing water temperatures may lower the recruitment of $S$. droebachiensis directly through its physiological effects (Stephens 1972), temperature increases may also indirectly affect post-settlement mortality through predation from new, more heat-tolerant predators (Blamey \& Branch 2012). The latitudinal distribution of marine species is strongly correlated to temperature tolerance, and increasing temperatures due to climate change may alter species distribution patterns (Lindley \& Kirby 2010), including the distribution of potential predators of sea urchins. A national report recently stated that more than 500 benthic marine species have extended their distribution farther north in Norway over the last 2 decades (Brattegard 2011). The ongoing recovery of kelp forests in central Norway coincides with large-scale changes in the abundance of Cancer pagurus (Woll et al. 2006, Norderhaug \& Christie 2009). Close relatives of this species have been identified as important predators of sea urchins in the NW Atlantic (Scheibling \& Hamm 1991, Siddon \& Witman 2004, McKay \& Heck 2008, Steneck et al. 2013) and the Pacific coast of North America (Clemente et al. 2013).

The aim of this study was to explore the effect of predators on sea urchin recruits in an area where sea urchin populations are presently collapsing. We focused on the effect of predation on newly settled and juvenile stages of the sea urchin Strongylocentrotus droebachiensis and how the structural complexity of the habitat may affect predation on sea urchins. More specifically, we aimed to: (1) identify potential sea urchin predators, (2) test how sea urchin size and (3) habitat affects sea urchin predation rates, i.e. how structurally complex kelp forest compares to low complexity barren ground, and finally (4) assess how the habitat affects the abundance and diversity of sea urchin predators.

\section{MATERIALS AND METHODS}

Due to the inherent difficulty of studying sea urchins in their early life stages, a combination of laboratory and field experiments was used in order to determine predator-prey interactions. Through field experiments, we sought to study predation in a realistic context where potential predators participate in complex biological interactions while laboratory experiments allowed us to manipulate predator-prey interactions under controlled conditions.

\section{Study area for field surveys}

Field experiments were performed in the sub-tidal areas north of Vega Island $\left(65^{\circ} 70^{\prime} \mathrm{N}\right)$. Vega is part of an archipelago in the Norwegian Sea and represents the present, southern border of the barren ground area, where kelp forest is currently recovering (Fig. 1). Field surveys and experiments were conducted at 6 study sites comprising 3 replicate barren ground sites and 3 replicate kelp forest sites (Fig. 1). Laminaria hyperborea was the dominant algal species at the kelp forest sites while kelp were absent from the barren ground sites. Water depth was approximately $5 \mathrm{~m}$ at high tide at all study sites. 


\section{Identifying potential predators in situ}

Roofing tiles were positioned at each replicate study site, where the underside served as a spatial refuge and a standardized sampling unit. The intention was to imitate a natural refuge where juvenile sea urchins may encounter their potential predators. The selection of potential predators for subsequent laboratory experiments was based on species observed under the roofing tiles combined with knowledge gained from similar laboratory experiments (McNaught 1999, Scheibling \& Robinson 2008, Bonaviri et al. 2012) and biodiversity studies from Norwegian kelp communities (e.g. Norderhaug et al. 2002, Christie et al. 2003). Five replicate tiles (420 x $330 \mathrm{~mm}$ ) were placed on the sea floor at each station. The tiles were deployed in May 2008, and the fauna present underneath each tile was recorded in the fall (September) and spring (May) for 2 subsequent years (4 observations in total). SCUBA divers carefully removed each tile and identified and counted all animals before the tile was gently returned to its original position. Spatial variability in the abundance of potential sea urchin predators was compared between kelp forest and barren ground, and the abundance of juvenile sea urchins $(<2 \mathrm{~cm})$ co-occurring with the potential predators was estimated. Densities are given as ind. $\mathrm{m}^{-2}$.

\section{Laboratory experiments}

Juvenile Strongylocentrotus droebachiensis (2-3 mm in test diameter) were exposed to benthic invertebrates in laboratory experiments performed at NIVAs Marine Research Station at Solbergstrand. Five species that potentially prey on sea urchins (Pagurus bernhardus (Linnaeus, 1758), Hyas araneus (Linnaeus, 1758), Nereis pelagica (Linnaeus, 1758), Carcinus maenas (Linnaeus, 1758) and Cancer pagurus were selected based on information from the literature (McNaught 1999, Scheibling \& Robinson 2008, Bonaviri et al. 2012) and the observations from the field surveys (see above) and were included in the trials as potential predators. Adult C. pagurus are much larger than adult specimens of the other predators tested; hence, juvenile $C$. pagurus were used in the experiments to obtain similar predator sizes. Two treatments were employed: with and without alternate prey. Juvenile Mytilus edulis (Linnaeus, 1758) were offered as the alternate prey. The mussels were approximately the same size as the sea urchin subjects and are common in the subtidal and inter- tidal zone. Predators and mussels were collected by SCUBA divers in Vega and kept in containers with seawater during transport to the laboratory. Carapace width (CW) of the decapod predators was measured after each trial. The sea urchins used in laboratory experiments were hatchery reared (Troms Kråkebolle AS) and were similar in size. The urchins were kept together in tanks and fed with the red algae Palmaria palmata before being used in the trials. The potential predators were fed pieces of shrimp every second day and deprived of food for $24 \mathrm{~h}$ prior to the trials. The 2 species of crab were monitored several days before the trials to ensure that they had not recently moulted or were not likely to moult during the trial. Predators were held in separate tanks with flowing sea water at $9^{\circ} \mathrm{C}$ before and during the experiments.

In the first treatment, 10 Strongylocentrotus droebachiensis were placed together in a small tank $(13 \times$ $13 \times 21 \mathrm{~cm}$ with an outflow at $10 \mathrm{~cm}$ height) and a single predator was added. In the second treatment, 10 Mytilus edulis were added together with 10 S. droebachiensis and 1 predator species. To prevent the sea urchins from escaping the tank and due to variation in size between predators, a fine-mesh net $(150 \mu \mathrm{m})$ served as a lid that sealed the tank. The net was lowered slightly in the tank in trials with the smallest predators so that predators on the underside of the net potentially could reach the prey. A natural day and night light cycle was maintained during the experiments. After $48 \mathrm{~h}$, the predator was removed and the tank and predator were carefully searched for surviving prey or remains. New individuals of prey and predators were used in each replicate trial (see Table 3 for the number of replicate trials for each predator species). Controls were run in parallel to the experiments where $S$. droebachiensis or $S$. droebachiensis and $M$. edulis were present without a predator.

\section{Tethering experiments}

Tethering experiments were used in addition to laboratory experiments to determine daily mortality rates of tethered sea urchins and to identify predators in their natural habitat. Tethering is a simple method to compare relative predation intensity on sedentary prey (Aronson et al. 2001) and has been used with sea urchins in several studies (McClanahan \& Muthiga 1989, Shears \& Babcock 2002, Guidetti 2006, Clemente et al. 2011). We used juvenile Strongylocentrotus droebachiensis from 2 size classes (small: $10( \pm 2) \mathrm{mm}$ test diameter and medium: $20( \pm 2) \mathrm{mm}$ 
test diameter) to test the effect of sea urchin size on predation rates.

A hypodermic needle $(0.6 \times 38 \mathrm{~mm})$ was carefully inserted through the dorsal and ventral surface of the test sea urchins, as far away from the oral-aboral section as possible (McClanahan \& Muthiga 1989). A $0.2 \mathrm{~mm}$ nylon monofilament was then threaded through the needle and tied up. Survival rates of tethered sea urchins were tested in laboratory trials where we found $100 \%$ survival of 15 sea urchins (20-50 mm) after $20 \mathrm{~d}$. The tethered sea urchins were monitored daily, enabling identification of individuals critically injured from the tethering procedure. The sea urchins used in field experiments were tethered and kept in seawater $24 \mathrm{~h}$ prior to the trial in order to minimize leakage of coelomic fluids (cf. McClanahan \&

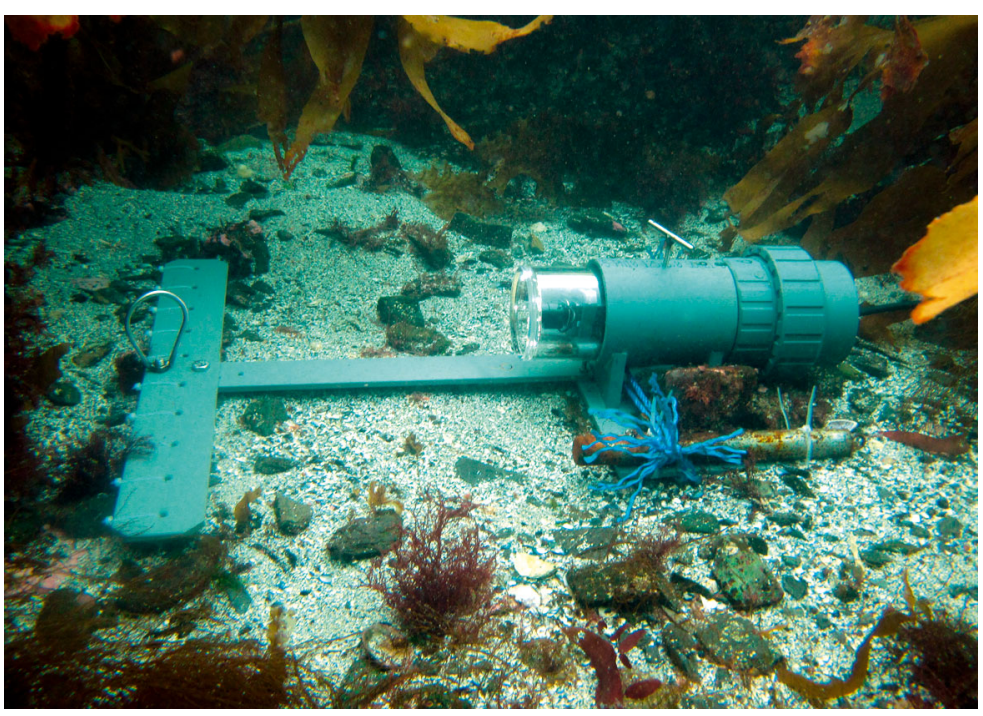

Fig. 2. Experimental setup used for monitoring tethered sea urchins in field experiments. The camera is positioned to the right while the plate for tethering sea urchins is seen on the left
Muthiga 1989). Before the monofilament was tied to a plate in front of a submersible video camera, we ensured that the sea urchins were alive and moving their spines and tube feet. Five small (10 $\mathrm{mm})$ and 5 medium $(20 \mathrm{~mm})$ sized sea urchins were tethered at each station (10 sea urchins in total). The monofilament was approximately $6 \mathrm{~cm}$ long and allowed the sea urchins some mobility. The exposure to natural predators lasted $24 \mathrm{~h}$ and was repeated 3 times. Both consumed and unharmed sea urchins were replaced by new individuals before the onset of a new trial. Daily mortality rates were determined by counting the number of surviving sea urchins every $24 \mathrm{~h}$. The mortality rates of Strongylocentrotus droebachiensis were compared between habitats and size classes. The actual attack by the predator was in some incidents not positively identified from the video due to algae sweeping in front of the camera or by the assumed predator blocking the field of view. In such cases, the identity of the predator was determined from observations of possible predators occupying the spot where the sea urchin was attached.

Each station was monitored by camera for a minimum of $18 \mathrm{~h}$, providing information of the identity of the predators during the time sequence. Fig. 2 shows the experimental setup. The cameras were equipped with a light to obtain a visible film throughout the nocturnal cycle. Due to storage failure, videos were deleted from some memory cards; hence video recordings were analysed from 10 of the 18 trials. From the remaining trials without video recording, only daily mortality rates were estimated.

\section{Statistical analysis}

All statistical tests were conducted with $\mathrm{R}$ 2.15.3 (www.r-project.org). From the total presence of species observed underneath roofing tiles, only invertebrates interacting/preying on sea urchins in laboratory and/or tethering experiments were included in statistical analysis. To analyse variability in the abundance of potential predators and juvenile sea urchins $(<2 \mathrm{~cm})$, separate generalized linear mixed models (GLMM) were used. Explanatory factors included in the models were 'habitat' (fixed effect with 2 levels: barren ground and kelp forest) and 'season' (fixed effect with 2 levels: fall and spring). The explanatory factors 'study site' (6 levels: Stns V1-V6) and 'visit' (4 levels representing the 4 observation times) were included as crossed random factors to control for within-subject co-variability due to repeated measurements. The glmmADMB package from the AD Model Builder (Fournier et al. 2012) was used for the analysis, as it allowed for a negative binomial distribution and 2 random effects.

Consumption of sea urchins in laboratory experiments was analysed with generalized linear model (GLM) analysis due to the binomially distributed dependent variable $(x / 10$ sea urchins eaten). The explanatory variables 'Predator species' and 'Treatment' were treated as fixed factors, where the 2 levels of 'Treatment' refer to trials with and without Mytilus edulis present. The interaction between predictors was included in the full model. To control for the effect of differing size $(\mathrm{CW})$ between crab preda- 

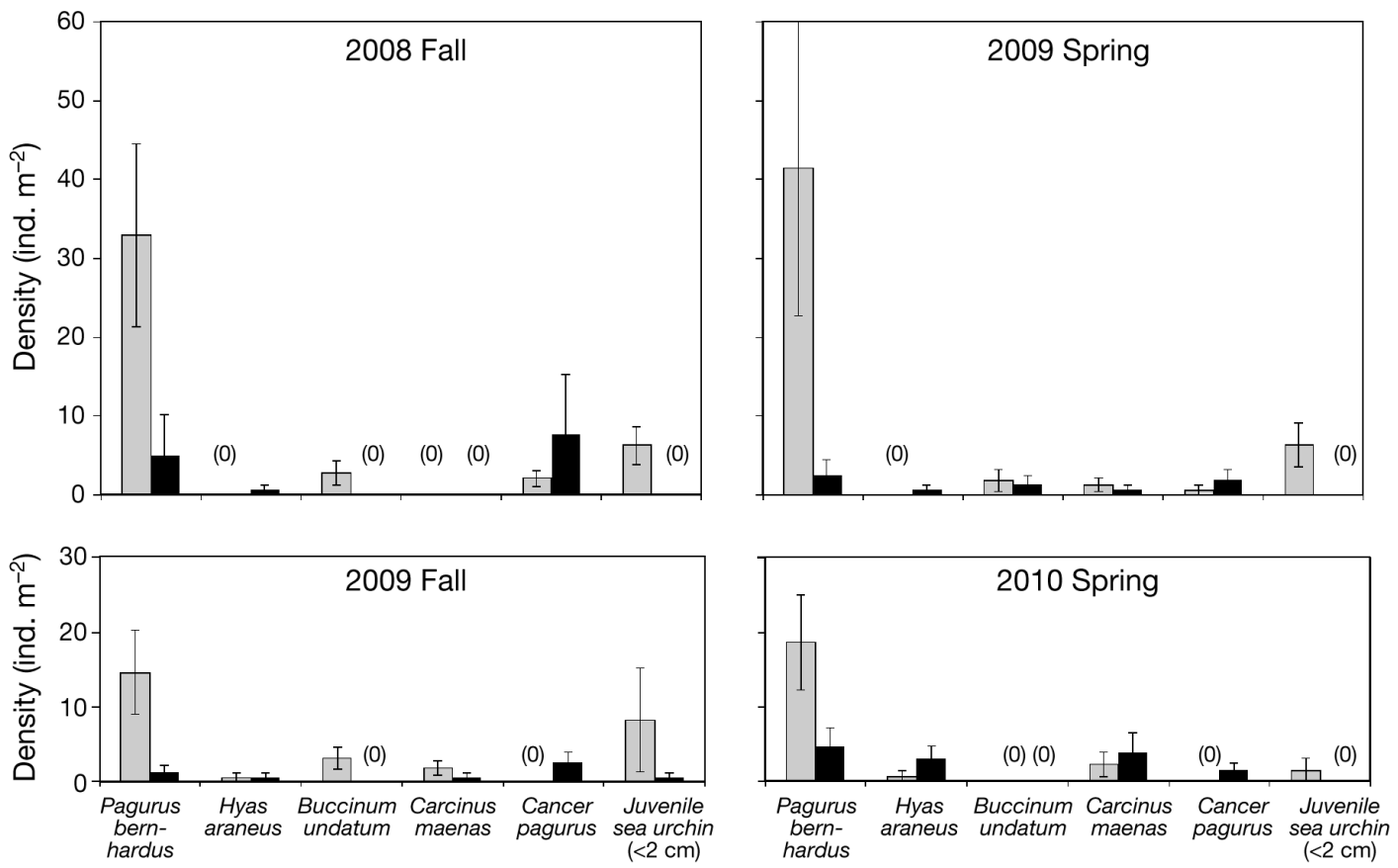

Fig. 3. Mean $( \pm \mathrm{SE})$ density (ind. $\mathrm{m}^{-2}$ ) of different species inhabiting roofing tiles in barren ground $(\mathrm{n}=15$, grey bars) and kelp forest ( $\mathrm{n}=15$, black bars) habitats on 4 different sampling occasions. Sample sizes were reduced on barren ground in fall 2009 and spring 2010 due to loss of roofing tiles $(n=12)$ tors (Hyas araneus, Cancer pagurus and Carcinus maenas), a separate GLM was run wherein CW was included in the model as a controlling continuous variable. The significance of size was examined using a likelihood ratio test.

To test for differences in sea urchin survival among 2 size classes and 2 types of habitats in tethering experiments, we used a GLMM. Because the experiment was repeated over $3 \mathrm{~d}$, we included a dependence structure by using 'study site' (6 levels: Stns V1-V6) and 'day' (3 levels: Day 1-3) as random factors. The explanatory variables 'habitat' (2 levels: kelp forest and barren ground) and 'size' (2 levels: small and medium) were included as fixed factors. The function Glmer from the lme4 package (Bates et al. 2012) was used for the analysis, which allowed for binomially distributed response variables and random effects. All possible interactions were included in the full model, and Akaike's information criterion (AIC) was used to select between candidate models.

\section{RESULTS}

\section{Potential predators - abundance and co-occurrence with juvenile sea urchins}

With one exception, no juvenile sea urchins were found under roofing tiles in kelp forest, while individuals from all predator species were identified in both habitats, although not in all sampling periods
(Fig. 3). Juvenile Strongylocentrotus droebachiensis and one of the potential predators (Pagurus sp.) were significantly more abundant under the roofing tiles at the barren ground sites than at the kelp forest sites (Table 1). Cancer pagurus showed the opposite pattern and was significantly more abundant within the kelp forest than on barren ground. The remaining predators showed no significant differences in mean abundance between barren ground and kelp forest sites. Three roofing tiles were lost during the study at one of the barren ground stations, probably due to storms and strong wave action.

\section{Laboratory experiments}

All decapod crustacean species tested in laboratory experiments consumed juvenile Strongylocentrotus droebachiensis (Fig. 4a,b), and Cancer pagurus consumed significantly more sea urchins than all other predators tested (Table 2). The presence/absence of Mytilus edulis ('Treatment') did not affect the consumption of sea urchins by $C$. pagurus as a main effect (Table 2). In contrast, the consumption of sea urchins by Hyas araneus and Pagurus bernhardus was significantly affected by the presence of $M$. edulis; thus the significant effect of 'Treatment' manifested in the form of an interaction with predator species (Table 2). $P$. bernhardus consumed fewer sea urchins in the presence of $M$. edulis, whereas $H$. araneus consumed more sea urchins when $M$. edulis 
Table 1. Abundance of Pagurus sp., Cancer pagurus, and Strongylocentrotus droebachiensis $(<2 \mathrm{~cm})$ predicted from generalized linear mixed model analyses. Parameter estimates, SE estimates and $\mathrm{p}$-values for the fixed predictors 'habitat' (baseline: barren ground) and 'season' (baseline: spring) are provided. Variance and SD are provided for the random effects 'study site' (6 in total) and 'visit' (1-4)

\begin{tabular}{|lrrrrrr|}
\hline Fixed effect & $\begin{array}{r}\text { Parameter } \\
\text { estimate }\end{array}$ & SE & $p$ & $\begin{array}{c}\text { Random } \\
\text { effect }\end{array}$ & Variance & SD \\
\hline Pagurus sp. & & & & & & \\
Intercept & 3.40 & 0.44 & $<0.0001$ & Site & $4.1 \times 10^{-9}$ & $6.4 \times 10^{-5}$ \\
Habitat & -2.09 & $0.52<0.0001$ & Visit & $3 \times 10^{-9}$ & $5.5 \times 10^{-5}$ \\
Season & -0.19 & 0.52 & 0.7100 & & & \\
Cancer pagurus & & & & & & \\
Intercept & -1.06 & 0.64 & 0.0990 & Site & $4.1 \times 10^{-9}$ & $6.5 \times 10^{-5}$ \\
Habitat & 1.69 & 0.69 & 0.0200 & Visit & $3.2 \times 10^{-9}$ & $5.6 \times 10^{-5}$ \\
Season & 1.06 & 0.70 & 0.1270 & & & \\
Strongylocentrotus droebachiensis & & & & 1.05 \\
Intercept & 0.94 & 0.95 & 0.3226 & Site & 1.1 & \\
Habitat & -4.48 & 1.59 & 0.0049 & Visit & $2.4 \times 10^{-6}$ & $1.5 \times 10^{-6}$ \\
Season & 1.47 & 1.06 & 0.1665 & & & \\
\hline
\end{tabular}

\section{Tethering experiment}

The daily predation rates on tethered sea urchins ranged from 1.2 to 1.8 urchins $\mathrm{d}^{-1}$ (Fig. 5), but we found no significant difference in sea urchin survival between habitats (i.e. barren ground versus kelp) or between urchin size classes (Table 4). Buccinum undatum, Carcinus maenas and Cancer pagurus preyed on and/or interacted with the tethered sea urchins most frequently on the videos. Sea urchin predators could be identified from film recordings in 21 of 52 incidents of predation. Of these sea urchins, $47.6 \%$ were consumed by $C$. maenas, while the remaining $52.4 \%$ were consumed by $C$. pagurus. The whelk $B$. undatum was occasionally observed to interact and attack tethered sea urchins in the videos, but these attacks were probably not fatal. The attacked sea urchins appeared unharmed and alive, or they were eaten by a decapod predator before any damage inflicted by the whelk could be determined.

The video recordings also revealed a high abundance of fish, especially shoals of cod Gadhus morhua and pollock Pollachius pollachius. Hermit crabs were also seen at fairly high densities at several of our study sites. None of these species was observed preying on sea urchins. Cancer pagurus appeared to be an efficient sea urchin predator from the video recordings because the same individuals were observed preying on several sea urchins during the were therefore excluded from GLM analysis.

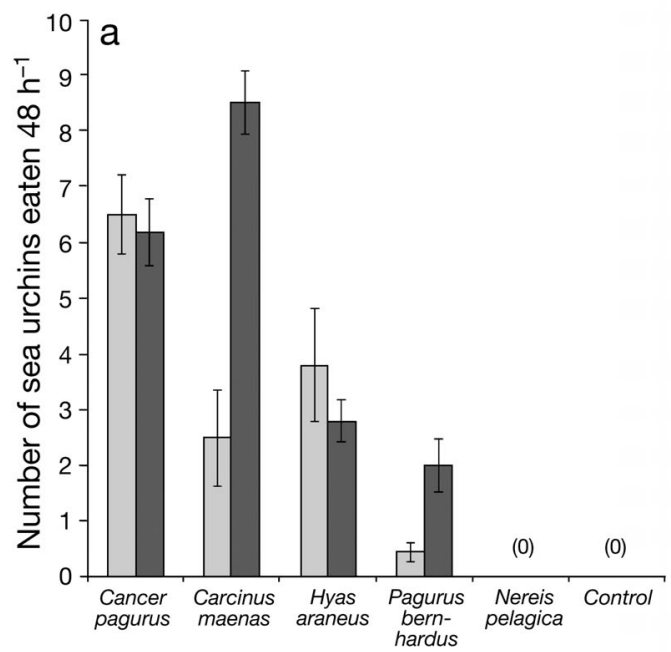

Fig. 4. Strongylocentrotus droebachiensis. Mean ( \pm SE) mortality of sea urchins (grey bars) in treatments (a) with Mytilus edulis present (gray bars) and (b) without M. edulis. Predators are shown on the $x$-axis 
Table 2. Parameter estimates, SE estimates and p-values for generalized linear model analysis of sea urchin mortality in laboratory experiments predicted by individual predators and treatment with interactions

\begin{tabular}{|c|c|c|c|}
\hline Fixed effects & Parameter estimate & SE & $\mathrm{p}$ \\
\hline Intercept & 0.56 & 0.13 & $<0.0001$ \\
\hline Predator $($ Cancer pagurus $=0$, Carcinus maenas $=1)$ & -2.76 & 0.44 & $<0.0001$ \\
\hline Predator (Cancer pagurus $=0$, Hyas araneus $=1)$ & -3.74 & 0.73 & $<0.0001$ \\
\hline Predator $($ Cancer pagurus $=0$, Pagurus bernhardus $=1)$ & -1.25 & 0.30 & $<0.0001$ \\
\hline Treatment (Mytilus edulis absent $=0$, Mytilus edulis $=$ present $)$ & 0.06 & 0.19 & 0.7520 \\
\hline Predator Carcinus maenas: Treatment Mytilus edulis present & 1.04 & 0.54 & 0.0536 \\
\hline Predator Hyas araneus: Treatment Mytilus edulis present & 2.62 & 0.80 & 0.0010 \\
\hline Predator Pagurus bernhardus: Treatment Mytilus edulis present & -2.44 & 0.61 & $<0.0001$ \\
\hline
\end{tabular}

Table 3. Species used in laboratory experiments to identify micropredators of juvenile Strongylocentrotus droebachiensis $(<3 \mathrm{~mm})$ in the presence/absence of Mytilus edulis. Size: carapace width range (total length for Pagurus bernhardus and Nereis pelagica); n: number of replicates

\begin{tabular}{|llcc|}
\hline Treatment & Species & Size (mm) & $\mathrm{n}$ \\
\hline With & Cancer pagurus & $14-76$ & 22 \\
M. edulis & Carcinus maenas & $30-42$ & 8 \\
& Hyas arenarius & $20-60$ & 5 \\
& Pagurus bernhardus & $20-50$ & 9 \\
& Nereis pelagica & & 6 \\
& Control & & 10 \\
Without & Cancer pagurus & $19-82$ & 25 \\
M. edulis & Carcinus maenas & $31-52$ & 6 \\
& Hyas arenarius & $44-58$ & 5 \\
& Pagurus bernhardus & $30-50$ & 6 \\
& Nereis pelagica & & 6 \\
& Control & & 11 \\
\hline
\end{tabular}

same trial. In comparison, Carcinus maenas was a more frequently observed predator. Their individual consumption rate was difficult to estimate since 2 or more individuals were frequently present and they moved back and forth into the field of view, making it difficult to determine whether it was the same or a new individual appearing. The trials did not reveal any size-specific preferences from the predators since they were observed preying on both size classes of sea urchins. C. pagurus were observed consuming 6 medium sized $(20 \mathrm{~mm})$ and 5 small (10 mm) sea urchins, while C. maenas were observed consuming 5 from each size class.

\section{DISCUSSION}

The present study showed that recently settled sea urchins are vulnerable to a variety of predators. To assess predation pressure in relation to collapsing sea urchin populations and kelp forest recovery in central Norway, knowledge of the species inhabiting this area and their predation potential is needed. The decapod crustaceans identified as the main predators from the feeding experiments are common within areas where the kelp forest is recovering; they typically inhabit rocky substrata where they are likely to co-occur with recently settled sea urchins (Fig. 3). Predation rates differed among the predators, and juvenile Cancer pagurus appeared to be the most voracious predator with significantly higher attack rates compared to the other species tested (Table 2). Predation rates determined in laboratory experiments frequently over-estimate predation rates in situ, because external factors such as refuge availability and increased variation of prey and predators intervene with predation in situ (Siddon \& Witman 2004, Ling \& Johnson 2012). Nevertheless, the results indicate that a suite of small predators is capable of exerting predation pressure on newly recruited sea urchins.

The early post-settlement phase of sea urchins is difficult to monitor in the field, but predator-prey inter-

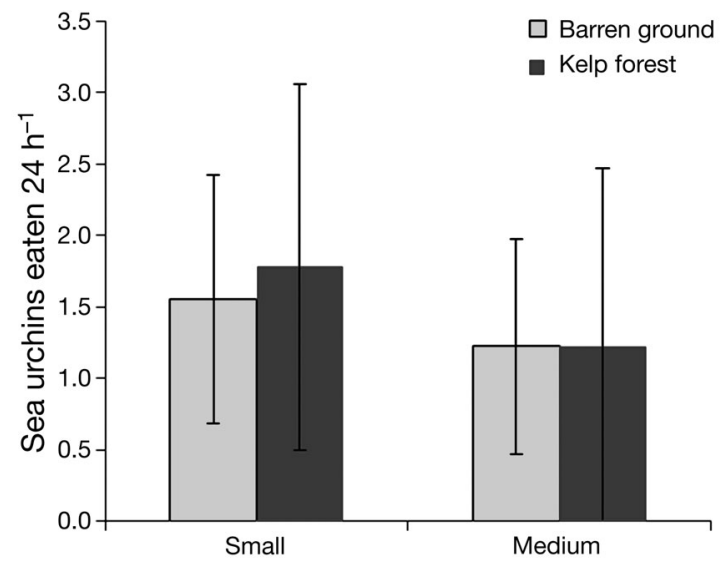

Fig. 5. Strongylocentrotus droebachiensis. Mean ( \pm SE) mortality of tethered sea urchins from 2 size classes (small: $10 \mathrm{~mm}$, medium: $20 \mathrm{~mm}$ test diameter) on barren ground (grey bars) and in kelp forest (grey bars) 
Table 4. Parameter estimates, SE estimates and p-values for predictors in generalized linear mixed model analysis of tethering experiments selected by Akaike's information criterion

\begin{tabular}{|lccc|}
\hline Fixed effects & $\begin{array}{c}\text { Parameter } \\
\text { estimate }\end{array}$ & SE & $\mathrm{p}$ \\
\hline Intercept & -1.46 & 0.91 & 0.111 \\
Habitat (Barren ground=0, & -0.21 & 1.26 & 0.866 \\
$\quad$ Kelp forest = 1) & & & \\
Size (Medium = 0, Small = 1) & 0.42 & 0.52 & 0.424 \\
Habitat: Size & 0.42 & 0.78 & 0.591 \\
\hline
\end{tabular}

actions using older juvenile sea urchins (10-20 mm test diameter) were monitored in a field-based tethering experiment. Tethering experiments have previously been successfully applied to test whether habitat-associated variation in predator assemblages and abundance may affect sea urchin predation rates and to determine the identity of the sea urchin predators (McClanahan \& Muthiga 1989, Vadas \& Steneck 1995, Shears \& Babcock 2002, Clemente et al. 2011). Tethering allows individuals to be observed in their natural environment where a complex interplay of factors may influence the predator-prey dynamics. The predation rate on tethered sea urchins was high in comparison to a similar experiments performed in the NW Atlantic by Vadas \& Steneck (1995). Video recordings from our tethering experiment confirmed that both Cancer pagurus and Carcinus maenas prey on young sea urchins in the field. However, these videos did not reveal any predation from the other small predators included in laboratory trials. Lack of predation from Hyas sp. and Pagurus sp. could be a result of a more complex food web, where the presence of other species indirectly modifies predation behaviour (cf. Werner \& Peacor 2003, Clemente et al. 2011). For example, Siddon \& Witman (2004) observed lower predation on Strongylocentrotus droebachiensis by the crab Cancer borealis in the presence of lobster Homarus americanus than without lobsters. However, the larger size of the tethered sea urchins when compared to those used in laboratory experiments may also account for the lack of predation by some predator species, as the sea urchins may have reached a size at which they escape predation from relatively small predators (Clemente et al. 2013). The escape size for sea urchin predated upon by Hyas araneus and Pagurus bernhardus may lie within a range of $3 \mathrm{~mm}$ (sea urchins used in laboratory experiments) to $10 \mathrm{~mm}$ (smallest size class of tethered sea urchins). Scheibling \& Robinson (2008) studied predation from hermit crabs $P$. acadianus on different size classes of sea urchins and found that they were less likely to be consumed as they increased in size. The sea urchins appeared to reach a size at which they could avoid predation from hermit crabs when the test diameter exceeded $\sim 10 \mathrm{~mm}$. Depending on nutrient supply, early life-stage $S$. droebachiensis increase their test diameter from 1 to $17 \mathrm{~mm}$ annually (Grieg 1928, Himmelman 1986). Given such a slow growth rate, the combined influence from many small predators may influence recruitment and survival of juveniles over a fairly long period of time.

A larger body size and larger claws enable Carcinus maenas and especially Cancer pagurus to handle larger prey than smaller predators, which will prolong their predation window on sea urchins relative to that of smaller predators. Neither C. maenas nor $C$. pagurus favoured small sea urchins over the medium sized individuals in the tethering experiment, although Scheibling \& Robinson (2008) found that only large adult sea urchins exceeding $50 \mathrm{~mm}$ in test diameter were able to reach a size refuge from large decapod crabs. Bimodal size structures in sea urchin populations have been attributed to large predation pressure on intermediate size classes in several studies (Tegner \& Dayton 1981, Sala \& Zabala 1996, Shears \& Babcock 2002). Very small, juvenile sea urchins may hide efficiently from many predators, but will outgrow their microhabitat refuges and become exposed to predators (Ling \& Johnson 2012) while larger urchins escape predation due to their size.

Unlike Strongylocentrotus droebachiensis, which is a cold water species (Stephens 1972), the northward distribution of the crab Cancer pagurus is limited by low temperatures (Lindley et al. 1993, Weiss et al. 2009). Climate change has great impact on species distributions, and the ongoing warming of the sea has proven to affect sea urchin-predator dynamics in both the northern and southern hemisphere (Ling \& Johnson 2012, Clemente et al. 2013). The range distribution of $C$. pagurus has recently expanded farther north in the NE Atlantic in correspondence with increasing ocean temperatures (Woll et al. 2006, Brattegard 2011). Crab stocks have also increased tremendously within the area of kelp recovery (H. Christie pers. obs., and information provided by local fishermen) as indicated by the annual landings of $C$. pagurus which have tripled in central Norway during the last decade (Woll et al. 2006). No quantitative data on changes in the Norwegian $C$. pagurus stocks exist and although the annual landings of crab have increased substantially in central Norway over the last $25 \mathrm{yr}$, estimating stock size 
development from increasing landings is inaccurate since the data are not standardized in catch per unit effort. Nevertheless, sustainable landings (cf. Woll et al. 2003) of thousands of tonnes of C. pagurus from the area where kelp forest is recovering underpin that $C$. pagurus is common within this area. An increase in the abundance of an efficient predator may potentially have a large impact on sea urchin population size and thus, on sea urchin-kelp dynamics. It therefore seems very likely that the recent recovery of the kelp forest in central Norway is partially driven by an increase in predation pressure on sea urchins. Similar scenarios are known from other locations. Steneck et al. (2013), for example, suggested that overexploitation of large, predatory fishes in the Gulf of Maine improved the recruitment of crab Cancer borealis, which has become the new apex predator controlling sea urchin abundance and maintaining the macroalgal state. Considering the results from our experiments in relation to an increase in crab abundance and declining sea urchin densities in central Norway, C. pagurus may have a similar important structural function.

The whelk Buccinum undatum was also observed interacting with the sea urchins during our tethering experiments. It is difficult to evaluate whether $B$. undatum exerts a genuine predation pressure on sea urchins or whether the observed interaction simply was an artifact of the puncture method and the tethering procedure. Neither Scheibling \& Robinson (2008) nor Scheibling \& Hamm (1991) found B. undatum to have an effect on sea urchin survival when tested in laboratory experiments. The risk of experimental artifacts is a disadvantage with all manipulative studies and must be taken into account when results are interpreted. Puncturing the sea urchin leads to leakage of body fluids; this may attract scavengers that do not normally prey on sea urchins. It may also intensify the rate of predation (McClanahan \& Muthiga 1989). Vadas \& Steneck (1995) confirmed a higher predation rate on tethered sea urchins by crab predators in the laboratory, as a result of tethering.

Although high habitat complexity, and thus high availability of shelter, may reduce predation and enhance the survival of juvenile sea urchins (Scheibling \& Hamm 1991, Hereu et al. 2005, Ling \& Johnson 2012, Clemente et al. 2013), complex macroalgal assemblages house a larger abundance and a greater diversity of fauna, and hence potential predators, than structurally simple barren ground habitats (Hauser et al. 2006, Christie et al. 2009, Norderhaug et al. 2012). A higher predation pressure is therefore also to be expected inside kelp forests under natural conditions (Hereu et al. 2005, Bonaviri et al. 2012). Sea urchin larvae tend to settle within both barren areas and kelp forests (Rowley 1989, Schroeter et al. 1996, McNaught 1999), but adult sea urchins are typically very rare inside the kelp forests (Skadsheim et al. 1995, Steneck et al. 2004). A number of studies imply that greater predation pressure within kelp forests may explain this pattern (Rowley 1989, McNaught 1999). Steneck et al. (2013) relocated high densities of adult sea urchins into intact macroalgal sites with a high abundance of the crab Cancer borealis. The abundance of sea urchins declined rapidly after the relocation, and predation by crabs on sea urchins was observed. The lack of difference in tethered sea urchin mortality between kelp forest and barren ground sites in the present study was therefore surprising (Fig. 5). The tethered prey may have been more visible to predators on the open barren ground than within dense kelp forest. Hence, predation-induced mortality could have been biased towards greater predation exposure on barren ground. Likewise, the abundance of predators underneath roofing tiles may suffer some among-treatment bias. There is a chance that the roofing tiles create 'hotspots' attracting invertebrates in search of shelter on a structurally simple barren ground. Although we observed a fairly uniform distribution of species between kelp forest and barren ground, the most efficient sea urchin predator, C. pagurus, was more frequently observed in kelp forest than on barren ground (Fig. 3). Due to frequent moulting as juveniles, C. pagurus seek shelter in crevices, among boulders and in kelp holdfast to protect themselves from predators (Woll \& van der Meeren 1997), hence they co-occur with sea urchins through multiple life phases. As crabs have become more abundant within the area where sea urchin recruitment is low (Fagerli et al. 2013), it is conceivable that crabs exert demographic effects on sea urchin populations and thereby function as a reinforcing mechanism of the kelp forest state.

Our findings document that several predators, and in particular, Cancer pagurus, are able to consume early life stages of Strongylocentrotus droebachiensis. The dramatic increase in the crab stock that has occurred over the last 1 to 2 decades coincides with the observed collapse of the sea urchin populations and the recovery of the kelp forests in the same area. Increasing top-down control on juvenile $S$. droebachiensis may initiate a cascading effect which may aid in the recovery of the kelp forests along the coast of central Norway. However, we emphasise that the identification of a potential predator does not auto- 
matically mean that this predator will have a strong top-down effect on the prey. Whether or not C. pagurus has a strong top-down effect on the sea urchins in central Norway depends upon the abundance of the predator and the prey, the functional response of the predator and on possible preferences for certain life stages of the prey and for other types of prey. Detailed surveys on predator and prey abundance, the numeric and functional response of the predator and population modeling are most likely needed to be able to finally document that the likelihood for kelp recovery and the resilience of the kelp forest are related to the presence of C. pagurus.

Acknowledgements. We thank E. Rinde, D.Ø. Hjermann and $\mathrm{H}$. Gundersen for constructive advice on statistical analysis. Thanks to J.T. Johansen at NIVAs Marine Research Station at Solbergstrand who helped and assisted in laboratory experiments. We also thank 3 anonymous reviewers who provided valuable comments to improve earlier versions of the manuscript. Funding was provided by the Research Council of Norway and NIVA as part of the project 'Habitat restoration in overgrazed areas on the northern Norwegian coast'.

\section{LITERATURE CITED}

Aronson RB, Heck KL Jr, Valentine JF (2001) Measuring predation with tethering experiments. Mar Ecol Prog Ser 214:311-312

Balch T, Scheibling RE (2001) Larval supply, settlement and recruitment in echinoderms. In: Lawrence JM, Jangoux $M$ (eds) Echinoderm studies, Vol 6. Balkema, Lisse, p 1-83

Bates D, Maechler M, Bolker B (2012) lme4: Linear mixedeffects models using $\mathrm{S} 4$ classes. $\mathrm{R}$ package version 0.999999-0. Available at http://CRAN.R-project.org/ package $=\operatorname{lme} 4$

Blamey LK, Branch GM (2012) Regime shift of a kelp-forest benthic community induced by an 'invasion' of the rock lobster Jasus lalandii. J Exp Mar Biol Ecol 420-421:33-47

Bonaviri C, Gianguzza P, Pipitone C, Hereu B (2012) Micropredation on sea urchins as a potential stabilizing process for rocky reefs. J Sea Res 73:18-23

Brattegard T (2011) Endringer i norsk marin bunnfauna 1997-2010. Utredning for DN 2011-8. Direktoratet for naturforvaltning, Trondheim

Christie H, Jorgensen NM, Norderhaug KM, WaageNielsen E (2003) Species distribution and habitat exploitation of fauna associated with kelp (Laminaria hyperborea) along the Norwegian coast. J Mar Biol Assoc UK 83:687-699

Christie H, Norderhaug KM, Fredriksen S (2009) Macrophytes as habitat for fauna. Mar Ecol Prog Ser 396: 221-233

> Clemente S, Hernández JC, Brito A (2011) Context-dependent effects of marine protected areas on predatory interactions. Mar Ecol Prog Ser 437:119-133

> Clemente S, Hernández JC, Montano-Moctezuma G, Russell MP, Ebert TA (2013) Predators of juvenile sea urchins and the effect of habitat refuges. Mar Biol 160: 579-590

Dayton PK (1975) Experimental studies of algal canopy interactions in a sea otter dominated kelp community at Amchitka-island, Alaska. Fish Bull 73:230-237

Estes JA, Tinker MT, Williams TM, Doak DF (1998) Killer whale predation on sea otters linking oceanic and nearshore ecosystems. Science 282:473-476

> Fagerli CW, Norderhaug KM, Christie HC (2013) Lack of sea urchin settlement may explain kelp forest recovery in overgrazed areas in Norway. Mar Ecol Prog Ser 488: 119-132

Fournier DA, Skaug HJ, Ancheta J, Ianelli J and others (2012) AD Model Builder: using automatic differentiation for statistical inference of highly parameterized complex nonlinear models. Optimiz Methods Softw 27:233-249

Grieg JA (1928) The Folden Fjord. Echinodermata. Tromsø Mus Skr 1:1-12

Guidetti P (2006) Marine reserves reestablish lost predatory interactions and cause community changes in rocky reefs. Ecol Appl 16:963-976

Harrold C, Pearce JS (1987) The ecological role of echinoderms in kelp forests. In: Jangoux M, Lawrence JM (eds) Echinoderm studies, Vol 2. Balkema, Rotterdam, p 137-233

Hauser A, Attrill MJ, Cotton PA (2006) Effects of habitat complexity on the diversity and abundance of macrofauna colonising artificial kelp holdfasts. Mar Ecol Prog Ser 325:93-100

> Hereu B, Zabala M, Linares C, Sala E (2004) Temporal and spatial variability in settlement of the sea urchin Paracentrotus lividus in the NW Mediterranean. Mar Biol 144:1011-1018

Hereu B, Zabala M, Linares C, Sala E (2005) The effects of predator abundance and habitat structural complexity on survival of juvenile sea urchins. Mar Biol 146:293-299

Himmelman JH (1986) Population biology of green sea urchins on rocky barrens. Mar Ecol Prog Ser 33:295-306

Lawrence JM (1975) On the relationships between marine plants and sea urchins. Oceanogr Mar Biol Annu Rev 13: 213-286

> Leinaas HP, Christie H (1996) Effects of removing sea urchins (Strongylocentrotus droebachiensis): stability of the barren state and succession of kelp forest recovery in the east Atlantic. Oecologia 105:524-536

Levitan DR (1988) Density-dependent size regulation and negative growth in the sea urchin Diadema antillarum Philippi. Oecologia 76:627-629

Lindley JA, Kirby RR (2010) Climate-induced changes in the North Sea Decapoda over the last 60 years. Clim Res 42: 257-264

> Lindley JA, Williams R, Hunt HG (1993) Continuous plankton records: anomalous seasonal cycles of decapod crustacean larvae in the North Sea plankton in an abnormally warm year. J Exp Mar Biol Ecol 172:47-65

$>$ Ling SD (2008) Range expansion of a habitat-modifying species leads to loss of taxonomic diversity: a new and impoverished reef state. Oecologia 156:883-894

Ling SD, Johnson CR (2012) Marine reserves reduce risk of climate-driven phase shift by reinstating size- and habitat-specific trophic interactions. Ecol Appl 22:1232-1245

Ling SD, Johnson CR, Frusher SD, Ridgway KR (2009) Overfishing reduces resilience of kelp beds to climate-driven catastrophic phase shift. Proc Natl Acad Sci USA 106: 22341-22345 
McClanahan TR, Muthiga NA (1989) Patterns of predation on a sea urchin, Echinometra mathaei (Deblainville), on Kenyan coral reefs. J Exp Mar Biol Ecol 126:77-94

McKay KM, Heck KL Jr (2008) Presence of the Jonah crab Cancer borealis significantly reduces kelp consumption by the green sea urchin Strongylocentrotus droebachiensis. Mar Ecol Prog Ser 356:295-298

McNaught DC (1999) The indirect effects of macroalgae and micropredation on the post-settlement success of the green sea urchin in Maine. PhD dissertation, The University of Maine, Orono, ME

Norderhaug KM, Christie HC (2009) Sea urchin grazing and kelp re-vegetation in the NE Atlantic. Mar Biol Res 5: 515-528

> Norderhaug KM, Christie H, Rinde E (2002) Colonisation of kelp imitations by epiphyte and holdfast fauna; a study of mobility patterns. Mar Biol 141:965-973

> Norderhaug KM, Christie H, Andersen GS, Bekkby T (2012) Does the diversity of kelp forest macrofauna increase with wave exposure? J Sea Res 69:36-42

Prado P, Tomas F, Pinna S, Farina S and others (2012) Habitat and scale shape the demographic fate of the keystone sea urchin Paracentrotus lividus in Mediterranean macrophyte communities. PLoS ONE 7:e35170

Raymond BG, Scheibling RE (1987) Recruitment and growth of the sea urchin Strongylocentrotus droebachiensis (Müller) following mass mortalities off Nova Scotia, Canada. J Exp Mar Biol Ecol 108:31-54

Rodríguez SR, Ojeda FP, Inestrosa NC (1993) Settlement of benthic marine invertebrates. Mar Ecol Prog Ser 97: 193-207

Roughgarden J, Gaines S, Possingham H (1988) Recruitment dynamics in complex life-cycles. Science 241:1460-1466

Rowley RJ (1989) Settlement and recruitment of sea urchins (Strongylocentrotus spp.) in a sea-urchin barren ground and a kelp bed: Are populations regulated by settlement or post-settlement processes? Mar Biol 100:485-494

Russell MP (1998) Resource allocation plasticity in sea urchins: rapid, diet induced, phenotypic changes in the green sea urchin, Strongylocentrotus droebachiensis (Müller). J Exp Mar Biol Ecol 220:1-14

Sala E, Zabala M (1996) Fish predation and the structure of the sea urchin Paracentrotus lividus populations in the NW Mediterranean. Mar Ecol Prog Ser 140:71-81

Scheibling RE (1986) Increased macroalgal abundance following mass mortalities of sea urchins (Strongylocentrotus droebachiensis) along the Atlantic coast of Nova Scotia. Oecologia 68:186-198

Scheibling RE, Hamm J (1991) Interactions between sea urchins (Strongylocentrotus droebachiensis) and their predators in field and laboratory experiments. Mar Biol 110:105-116

Scheibling RE, Robinson MC (2008) Settlement behaviour and early post-settlement predation of the sea urchin Strongylocentrotus droebachiensis. J Exp Mar Biol Ecol 365:59-66

Scheibling RE, Hennigar AW, Balch T (1999) Destructive grazing, epiphytism, and disease: the dynamics of sea urchin-kelp interactions in Nova Scotia. Can J Fish Aquat Sci 56:2300-2314

Schroeter SC, Dixon JD, Ebert TA, Rankin JV (1996) Effects of kelp forests Macrocystis pyrifera on the larval distribution and settlement of red and purple sea urchins
Strongylocentrotus franciscanus and $S$. purpuratus. Mar Ecol Prog Ser 133:125-134

Shears NT, Babcock RC (2002) Marine reserves demonstrate top-down control of community structure on temperate reefs. Oecologia 132:131-142

Siddon CE, Witman JD (2004) Behavioral indirect interactions: multiple predator effects and prey switching in the rocky subtidal. Ecology 85:2938-2945

Sivertsen K (1997a) Dynamics of sea urchins and kelp during overgrazing of kelp forests along the Norwegian coast. PhD thesis, University of Tromsø

Sivertsen K (1997b) Geographic and environmental factors affecting the distribution of kelp beds and barren grounds and changes in biota associated with kelp reduction at sites along the Norwegian coast. Can J Fish Aquat Sci 54:2872-2887

> Sivertsen K (2006) Overgrazing of kelp beds along the coast of Norway. J Appl Phycol 18:599-610

Skadsheim A, Christie H, Leinaas HP (1995) Population reductions of Strongylocentrotus droebachiensis (Echinodermata) in Norway and the distribution of its endoparasite Echinomermella matsi (Nematoda). Mar Ecol Prog Ser 119:199-209

Steneck RS, Graham MH, Bourque BJ, Corbett D, Erlandson JM, Estes JA, Tegner MJ (2002) Kelp forest ecosystems: biodiversity, stability, resilience and future. Environ Conserv 29:436-459

> Steneck RS, Vavrinec J, Leland AV (2004) Accelerating trophic-level dysfunction in kelp forest ecosystems of the western North Atlantic. Ecosystems 7:323-332

> Steneck RS, Leland A, McNaught DC, Vavrinec J (2013) Ecosystem flips, locks, and feedbacks: the lasting effects of fisheries on Maine's kelp forest ecosystem. Bull Mar Sci 89:31-55

Stephens RE (1972) Studies on the development of the sea urchin Strongylocentrotus droebachiensis. I. Ecology and normal development. Biol Bull (Woods Hole) 142: 132-144

Tegner MJ, Dayton PK (1981) Population structure, recruitment and mortality of two sea urchins (Strongylocentrotus franciscanus and $S$. purpuratus) in a kelp forest. Mar Ecol Prog Ser 5:255-268

Vadas RL, Steneck RS (1995) Overfishing and inferences in kelp sea urchin interactions. Elsevier Science Publ, Amsterdam

Weiss M, Thatje S, Heilmayer O, Anger K, Brey T, Keller M (2009) Influence of temperature on the larval development of the edible crab, Cancer pagurus. J Mar Biol Assoc UK 89:753-759

- Werner EE, Peacor SD (2003) A review of trait-mediated indirect interactions in ecological communities. Ecology 84:1083-1100

Witman JD (1985) Refuges, biological disturbance, and rocky subtidal community structure in New England. Ecol Monogr 55:421-445

Woll AK, Van der Meeren GI, Fossa I, Tveite S (2003) Preliminary results from a resource study of edible crab (Cancer pagurus) in Norway 2001-2003. Document CM 2003/Q:16. ICES, Copenhagen

> Woll AK, van der Meeren GI, Fossen I (2006) Spatial variation in abundance and catch composition of Cancer pagurus in Norwegian waters: biological reasoning and implications for assessment. ICES J Mar Sci 63:421-433 